\title{
ANÁLISE DA EFICIÊNCIA DO SISTEMA DE LODOS ATIVADOS POR MEIO DE MICROSCOPIA
}

\author{
Augusto Eduardo Schlegel \\ Leonardo Rodolfo Paul \\ Prof. Eliana V. Jaeger \\ Augugtoe.s@gmail.com \\ leeo nardorehotmail.com \\ elíana@ibnet.com.br
}

\begin{abstract}
RESUMO: A indústria necessita de muita água no seu processo produtivo e com isso ocorre a geração de efluentes. Uma das formas mais utilizadas para tratar essas águas residuárias é o tratamento biológico por meio de lodos ativados. Para que esse sistema atenda as expectativas ele necessita de uma boa depuração, ou seja, precisa ser eficiente. Dessa forma, o artigo tem como objetivo analisar a eficiência do sistema de lodos ativados por meio de microscopia, identificando os microorganismos presentes em uma amostra de lodo coletada em 12 de novembro de 2014 em uma indústria têxtil do Alto-Vale do Itajaí. Após a realização da microscopia os dados foram analisados e obteve-se um diagnóstico de problemas no tratamento.
\end{abstract}

Palavras-chave: Lodo. Microorganismos. Microscopia. Tratamento.

\section{INTRODUÇÃO}

A maior parte das águas residuais são geradas pelo esgoto doméstico e por atividades industriais, e quando não são tratadas tornam-se um forte vetor de doenças (DAVIES, 2005). Como solução existem os métodos de tratamento que utilizam de microorganismos para remover a poluição orgânica dos efluentes.

O sistema de lodos ativados é uma das formas de tratamento biológico de esgotos que é amplamente usada, visto que é uma ótima opção para efluentes que precisam de uma alta remoção de matéria orgânica, ao passo que é necessária uma pequena área para implantá-lo (BENTO et al., 2005).

Por conta do sistema ser exposto a diversas toxinas, principalmente em efluentes industriais, a sua microbiota pode não dar conta de tratar a água e sofrer um choque, matando vários dos microorganismos e prejudicando todo o processo (DAVIES, 2005). Por esse motivo a identificação da fauna microbiológica por microscopia é importante na monitoração do sistema. Levando em conta este fato, o trabalho tem como objetivo analisar a eficiência dos lodos ativados por meio de um estudo de caso da estação de tratamento de uma empresa têxtil do Alto Vale do Itajaí, na qual foi realizada uma microscopia de uma amostra de lodo cedida pela empresa e então foram identificados microorganismos que servem como parâmetros indicadores da qualidade do processo. 


\section{CARACTERÍSTICA DO SISTEMA DE LODOS ATIVADOS}

Basicamente o sistema é composto por um reator, um tanque de decantação e a retroalimentação do lodo ativado. No reator acontece a maior parte da degradação de matéria orgânica, realizada por uma flora microbiana diversificada. No decantador ocorre a sedimentação dos flocos, o que da origem aos lodos. Na retroalimentação, parte do lodo formado é retornado ao reator para melhorar a eficiência do processo, a parte que não será reutilizada vai para a etapa de tratamento e condicionamento de lodos. Esta última etapa é um dos maiores problemas a serem resolvidos, pois possui um custo alto (VON SPERLING, 2012).

O sistema de lodos ativados tem um funcionamento macroscópico, mas depende inteiramente de seres microscópicos que são os responsáveis pela degradação da matéria orgânica da água residuária. Segundo Mara; Horan (2003) estes seres são sensíveis a mudanças químico-físicas e a maior parte das alterações macroscópicas que aparecem no sistema são causadas por alterações na fauna microbiológica. Dessa forma, é necessário ter uma microbiota saudável para que haja um bom funcionamento de todo o processo de tratamento, então o monitoramento por microscopia desses organismos evitará que ocorra um colapso no sistema.

Como as bactérias são organismos extremamente pequenos e é necessário um equipamento mais caro para uma observação efetiva, os protozoários são usados como parâmetros para verificar a situação do depuramento do sistema de lodos ativados (CARDI et al., 2007). Ainda que as bactérias podem ser difíceis de observar em microscópios menos potentes é possível identificar colônias das mesmas quando há o problema de intumescimento do floco do lodo ativado.

\section{METODOLOGIA}

Do ponto de vista da abordagem a pesquisa é quantitativa e qualitativa. $\mathrm{O}$ primeiro, para Günther (2006), é uma pesquisa na qual os dados podem ser manipulados e exibidos estatisticamente, enquanto o segundo não consegue ser traduzido dessa forma.

Em termos de procedimento foi feito uma pesquisa experimental, o que para Gil (2008) é a observação dos efeitos de uma variável sobre um elemento, na qual há um controle dessas variáveis. Também há um estudo de caso que para Ventura (2007) é a intensa análise de um único caso para obter o maior número de informações possíveis e aproveita-las da melhor maneira.

A população amostrada é uma estação de tratamento por sistema de lodos ativados de uma empresa do ramo têxtil, localizada no Vale do Itajaí. A coleta da amostra foi realizada por um técnico responsável da estação de tratamento e depois foi cedida para a pesquisa.

\section{RESULTADOS E ANÁLISE DOS DADOS}

Para que a amostra de lodos ativados fosse observada no microscópio, foi realizada a desinfecção da lâmina e lamínula com álcool etílico $67 \%$ e após isso foram gotejadas duas gotas do lodo sobre a lâmina. As figuras a seguir foram obtidas na ocular do microscópio por meio de uma câmera de aparelho celular. 
Na figura 4 é possível observar um rotífero, um micrometazoário que aparece frequentemente em lodos de idade alta (BENTO et al., 2005). Os rotíferos são predadores e se alimentam de flocos pequenos e ciliados de tamanho maior, com isso acaba contribuindo na clarificação do efluente (ROSA; BAZZANELLA, 2009). Apesar de encontrá-lo na amostra ele não apareceu em abundância.

Figura 4: Rotífero identificado na amostra

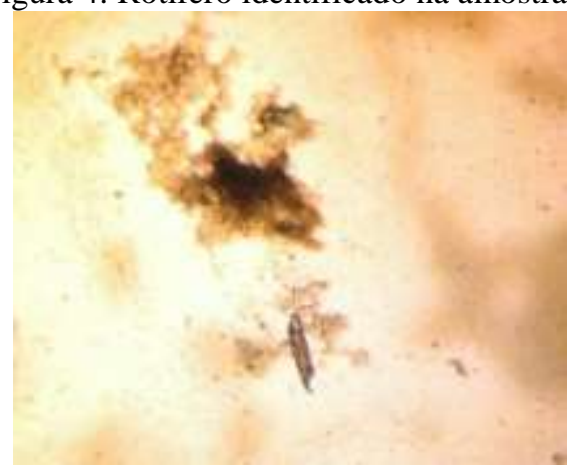

Fonte: dos autores.
Figura 5: Ciliado identificado na amostra

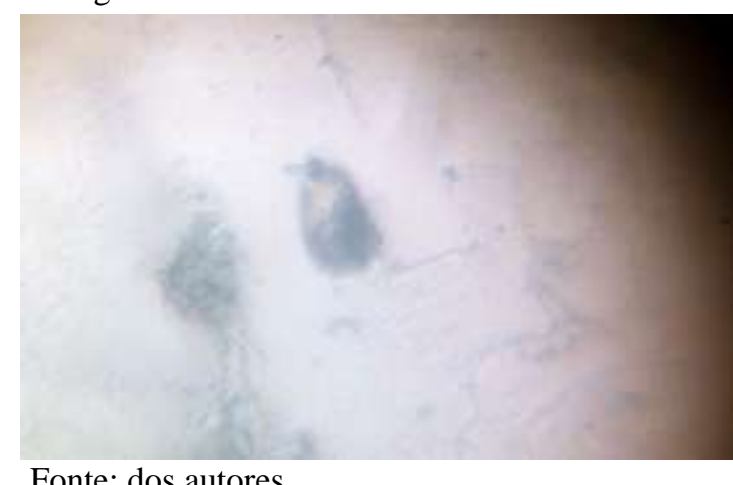

Fonte: dos autores.

Como se pode observar na figura 5, foram encontrados ciliados livres. Segundo Rosa; Bazzanella (2009) os ciliados são responsáveis pela redução na turbidez da água tratada, isso ocorre porque eles atuam na clarificação, consumindo os flocos que não são suficientemente densos para sedimentar e bactérias sobrenadantes, ambos responsáveis pelo aumento da turbidez.

Os flocos da amostra coletada estavam dispersos e não são encontradas muitas bactérias filamentosas, as quais são responsáveis pela estrutura do floco, aliada às bactérias formadoras de floco. Esse crescimento disperso é comum em efluentes industriais por causa da toxicidade e quantidade alta de matéria orgânica no efluente (RICHARD, 2003). Outro ponto relevante foi a baixa quantidade de protozoários identificados. A frequência baixa destes organismos nos lodos ativados pode indicar uma toxicidade alta no meio, condição adversa para o desenvolvimento de diversas formas de vida (RICHARD, 2003). No recipiente de coleta a amostra estava bem turva, o que condiz com o fato de existirem poucos microorganimos predadores no meio.

\section{CONCLUSÕES}

A análise microscópica é uma forma válida para identificar possíveis problemas no processo de tratamento de efluentes por sistema de lodos ativados. A monitoração constante pode otimizar o sistema e impede que a empresa libere efluentes fora das condições aceitáveis.

O objetivo da pesquisa foi alcançado ao realizar a análise do lodo obtidas através de microscopia e apresentar os indicadores encontrados na amostra, possibilitando um diagnóstico de problemas presentes no sistema de tratamento. De acordo com os indicadores encontrados e a situação do floco, a toxicidade do meio é alta, o que causa a morte de predadores de floco, responsáveis pela remoção da matéria orgânica em suspensão. Outro possível problema é a alta quantidade de matéria orgânica depositada no sistema em pouco tempo, criando flocos dispersos e pouco 
densos. Portanto, a eficiência do sistema não está otimizada e deve ser melhorada, pois uma depuração aquém do esperado nesse tipo de efluente causa impactos sérios no ecossistema, uma vez que efluentes têxteis possuem corantes difíceis de degradar naturalmente em um ecossistema estável; uma solução para isso é ajustar a relação A/M, para que então a floculação ocorra de forma ideal e evite a dispersão do floco.

Como houve dificuldade na coleta, uma vez que não foi permitido realiza-la pessoalmente, recomenda-se que outras pesquisas sejam feitas com acompanhamento da coleta, para certificar-se de que está sendo realizada adequadamente. Ainda, é interessante realizar análises de parâmetros físico-químicos como DBO, DQO e turbidez para correlacionar com a presença dos microorganimos e poder elaborar um diagnóstico mais completo.

\section{REFERÊNCIAS}

BENTO, A. P. et al. Caracterização da microfauna em estação de tratamento de esgotos do tipo lodos ativados: um instrumento de avaliação e controle do processo. Engenharia Sanitária e Ambiental, Florianópolis, v.10, n. 4, p. 329-338, out/ dez 2005.

CARDI, Livia et al. Intrumescimento filamentoso no processo de lodos ativados aplicado ao tratamento de soro de queijo: caracterização e uso de floculantes para melhorar a sedimentabilidade. Enganharia Ambiental, Espírito Santo do Pinhal, v. 4, n. 2, p. 026-037, jul/dez 2007.

DAVIES, P. S. The biological basis of wastewater treatment. Glasgow, Escócia, 2005, $20 \mathrm{p}$.

GIL, Antonio Carlos. Métodos e técnicas de pesquisa social. $6^{\text {a }}$ edição. São Paulo: Atlas, 2008, 200 p.

GÜNTHER, Hartmut. Pesquisa qualitativa versus pequisa quantitativa: esta é a questão? Psicologia: Teoria e Pesquisa, Brasília, v. 22, n. 2, mai/ago 2006, p. 201-210. Disponível em: < http://www.scielo.br/pdf/ptp/v22n2/a10v22n2> . Acessado em: $16 / 10 / 2014$.

MARA, D.; HORAN, N. Water and wastewater microbiology. Leeds: Academic Press, 2003, 610 p.

RICHARD, M. Activated sludge microbiology problems and their control. ANNUAL USEPA NATIONAL OPERATOR TRAINERS CONFERENCE, 20., 2003, Buffalo, Anais... Fort Collins: SEAR-BROWN, 2003.

ROSA, S. A. S.; BAZZANELLA, A. Microbiologia dos lodos ativados. 2009, 16 p. Públicado e disponível em:

<http://www.tratamentodeagua.com.br/r10/Lib/Image/bib_438528798_Microbiologia $\% 20$ dos\%20Lodos\%20Ativados.pdf> Acesso em: 15/11/2014. 


\section{1 Universidade do Estado de Santa Catarina \\ S Revité Cientitica do Airo Vale do ltapial Centro de Educacão Superior do Alto Vale do Itaiaí}

SPERLING, Marcos Von. Princípios do tratamento biológico de águas residuárias: lodos ativados. $3^{\text {a }}$ edição. Belo Horizonte: UFMG, 2012, 428 p.

VENTURA, Magda Maria. $O$ estudo de caso como modalidade de pesquisa.

RevSOCERJ, Rio do Janeiro, v. 20, n. 5, set/out 2007, p. 383-386. Disponível em:

<http://unisc.br/portal/upload/com_arquivo/o_estudo_de_caso_como_modalidade_de_p esquisa.pdf>. Acesso em: 16/10/2014. 